\title{
INVESTIGATION OF CRITICAL HEAT FLUX ON ABRADED INCONEL 625 TUBE
}

\author{
Ladislav SuK ${ }^{a}$, Kamil Števanka $^{a, *}$, Taron Petrosyan $^{a}$, Daniel VlČeK $^{b}$ \\ ${ }^{a}$ Brno University of Technology, Faculty of Electrical Engineering and Communication, Department of Electrical \\ Power Engineering, Technická 3058/10, 61600 Brno, Czech Republic \\ ${ }^{b}$ Czech Technical University in Prague, Faculty of Nuclear Sciences and Physical Engineering, Department of \\ Nuclear Reactors, Břehová 78/7, 11519 Prague, Czech republic \\ * corresponding author: kamil.stevanka@vutbr.cz
}

Abstract. Aim of this work was to study flow boiling in an annular channel at low pressure and low flow on a tube with modified surface roughness. The tube with the outer diameter of $9.14 \mathrm{~mm}$ and the heated length of $380 \mathrm{~mm}$ was made of Inconel 625 and was manually modified using 150 grit sandpaper. The tube was placed in a glass tube with an inner diameter of $14.8 \mathrm{~mm}$. Outlet pressure was set to 120 , 200 and $300 \mathrm{kPa}$ with varying mass flow from 400 to $600 \mathrm{~kg} /\left(\mathrm{m}^{2} . \mathrm{s}\right)$. A high speed camera was used to record several experiments to fully understand ongoing phenomena. Surface roughness was analysed using a confocal laser microscope and the effects of different mass flux and pressure on the CHF value were observed. Above all, the optimization of the flow parameters was done from the collected data and from the observed behaviour of the experimental loop.

KeYwords: Annulus, critical heat flux, flow boiling, Inconel 625.

\section{INTRODUCTION}

Departure from nucleate boiling decreases the heat transfer from the fuel cladding to the coolant, this in turn leads to a rapid increase of temperature and can cause failure of the material. Therefore, it is vital for nuclear reactor operation to avoid critical heat flux (CHF). It is important to maintain a safety margin to prevent possible fuel damage. Despite the fact that boiling crisis was researched extensively during the early development and deployment of PWR reactors, it is still being researched today, especially with the inception of accident tolerant fuels (ATF).

Boiling phenomena can be studied either in pool boiling arrangement or flow boiling. Equipment needed for pool boiling experiments is simpler and thus they are relatively accessible as they are usually performed at atmospheric pressure and on small steel plates or thin wires. Examples of recent pool boiling experiments aimed at comparing surface characteristics are the works by O'Hanley et al. [1, Kam et al. [2, Ali et al. [3] and Liang et al. [4].

Flow boiling experiments are more complex and harder to compare between each other, because the results depend on flow parameters such as mass flow, pressure, inlet temperature, as well as the geometry of a test section. Critical heat flux was researched broadly at high pressures [5], however there are far less available data on $\mathrm{CHF}$ at low pressures.

This work and test facility was inspired by Haas [6, 7, who carried out his experimental work at the COSMOS test facility at Karlsruhe Institute of Technology in Germany. Haas discovered that unstable flow conditions can occur without necessary precau- tions. These may lead to oscillations of the flow and premature CHF with much lower heat flux values.

Haas [7] conducted a thorough research of the flow boiling experiments at low flow and pressure performed, focusing mainly on annular geometry.

Chun [8] experimented with a wide range of pressures from $570 \mathrm{kPa}$ to $15010 \mathrm{kPa}$. Another investigation was done by Fiori and Bergles [9] who researched CHF in annular geometry at low pressures of $148-600 \mathrm{kPa}$. Experiments at pressures slightly above atmospheric pressure were done by El-Genk [10], Schoesse [11] and Rogers [12]. Each experiment at different mass fluxes but constant pressures of 118, 128 and $156 \mathrm{kPa}$, respectively. Rogers investigated CHF using Inconel 718. Other work includes the investigation of a very low subcooling of inlet water at the pressure of $100 \mathrm{kPa}$ by Mishima and Nushihara [13]. Mayer et al. [14] focused on the boiling crisis in an annulus at different mass fluxes and pressures between $110 \mathrm{kPa}$ and $225 \mathrm{kPa}$, the obtained data were afterwards compared with several correlations developed by the researchers mentioned above. More detailed description is provided in the paper by Vlcek et al. [15].

In this work, a set of experiments were performed on Inconel 625 with the roughness of the surface manually modified with 150 grit sandpaper. The experiments were conducted at different pressures, mass fluxes and inlet temperatures. Surface roughness was analyzed using a confocal laser microscope. High speed camera was used during the experiments to better understand the phenomena and improve the experimental setup. The aim of the work was to collect data on boiling crisis on the tube with increased roughness and opti- 

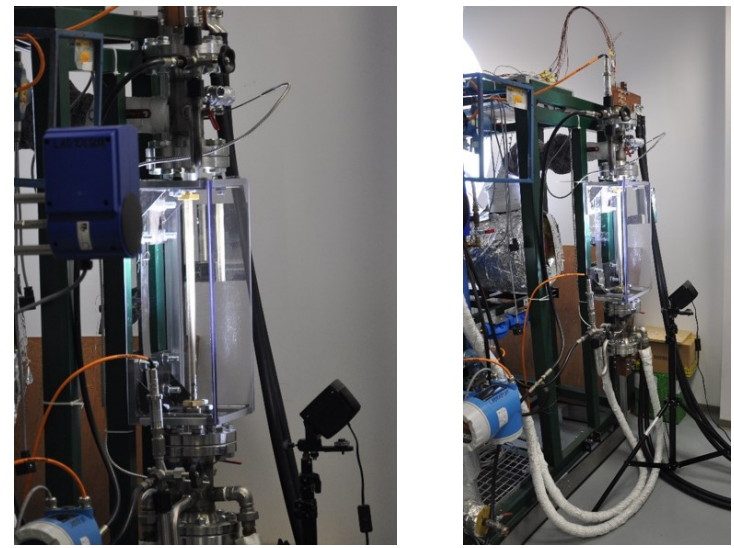

FiguRE 1. Setup for slow motion recording

mize the experimental procedure. The results will be compared to the CHF on other surfaces, unfortunately at the time of the conference only the experiments on sandpapered tube were measured and processed.

\section{EXPERIMENTAL SETUP}

Experiments were conducted on the Mobile Research Critical Heat Flux Apparatus (MRCHA) at BUT. The loop can operate at pressures of up to $1.5 \mathrm{MPa}$. DC power source was used to supply energy to the test section. DC power supply was tested up to $97.5 \mathrm{~kW}$ at $1500 \mathrm{~A}$ and $65 \mathrm{~V}$, furthermore for a short time it can provide up to $1700 \mathrm{~A}$ and $70 \mathrm{~V}$.

The CHF was detected using thermocouple probe which was fitted with 9 thermocouples (TCs). The test section consisted of a test tube that was pressed together with nickel-treated copper electrodes. The tube was placed in a glass tube, creating an annular geometry, and the probe was then placed inside the test section. The detailed description of the loop and measuring apparatus is provided in an article by Vlcek et al. 15. Two Inconel 625 tubes with an outer diameter of $9.14 \mathrm{~mm}$ were used for the experiments. The tubes were placed in a glass tube with an inner diameter of $14.8 \mathrm{~mm}$. All details of the annular geometry of the test section can be seen in Tab. 1.

\begin{tabular}{|c|c|}
\hline \multicolumn{2}{|l|}{ Parameter } \\
\hline Outer diameter $\mathrm{d}_{\text {out }}[\mathrm{mm}]$ & 14.8 \\
\hline Inner diameter $\mathrm{d}_{\text {in }}[\mathrm{mm}]$ & 9.14 \\
\hline Gap width $\delta[\mathrm{mm}]$ & 2.83 \\
\hline Heated length $[\mathrm{mm}]$ & 380 \\
\hline Wetted perimeter [mm] & 75.20 \\
\hline Heated perimeter $[\mathrm{mm}]$ & 28.71 \\
\hline Length to heated eq. diameter ratio $[-]$ & 25.63 \\
\hline Length to hydraulic diameter ratio $[-]$ & 67.13 \\
\hline Length to inner diameter ratio $[-]$ & 41.57 \\
\hline
\end{tabular}

TABLE 1 . The details of test annulus geometry.

Some of the experimental runs were recorded by the high speed camera, the information obtained will

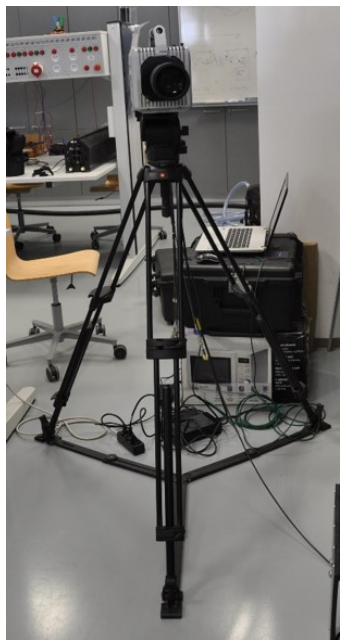

Figure 2. Photron High Speed Camera FASTCAM SA1.1

be discussed later. The test section and recording apparatus can be seen in Figs. 1 and 2 .

The roughness of the tubes was increased with 150 grit sandpaper, the resulting modification can be seen in Figs. 3 and 5 . Sandpapering was done manually at a $45^{\circ}$ angle to the vertical axis, see Fig. 4 . Surface roughness measurements were performed by a confocal laser microscope Olympus Lext OLS4100 according to CSN EN ISO 4288 standard [16]. The samples were cleaned with demineralized water and isopropyl alcohol before the measurements. Comparison of roughness of smooth and sandpapered tube is in the Tab. 2

\begin{tabular}{lcccc}
\hline Material & $\begin{array}{c}\mathrm{R}_{z} \\
{[\mu \mathrm{m}]}\end{array}$ & $\begin{array}{c}\mathrm{R}_{s} m \\
{[\mu \mathrm{m}]}\end{array}$ & $\begin{array}{c}\mathrm{R}_{t} \\
{[\mu \mathrm{m}]}\end{array}$ & $\begin{array}{c}\mathrm{R}_{a} \\
{[\mu \mathrm{m}]}\end{array}$ \\
\hline Smooth tube & 3.937 & 77.74 & 4.803 & 0.437 \\
Abraded tube & 8.173 & 97.02 & 8.640 & 0.771 \\
\hline
\end{tabular}

TABlE 2. Roughness

\section{Methodology}

Thirty one experiments were performed at different pressures, mass fluxes and inlet temperatures. The start-up sequence has been optimized to avoid excessive oscillations in the test section during the experiments. In instances when start-up sequence was rushed, CHF values could be as low as half of the average value obtained during standard operation, thus producing unreliable values. The oscillations were induced by insufficiently heated backflow valve, condenser and inlet hoses. The inlet hoses started to vibrate if the start-up sequence was rushed. If there was no steam in the condenser, the backflow valve had the tendency to periodically close.

These issues were solved by heating up the test section and loop for at least 15 minutes every time before ramping up the power supply. 


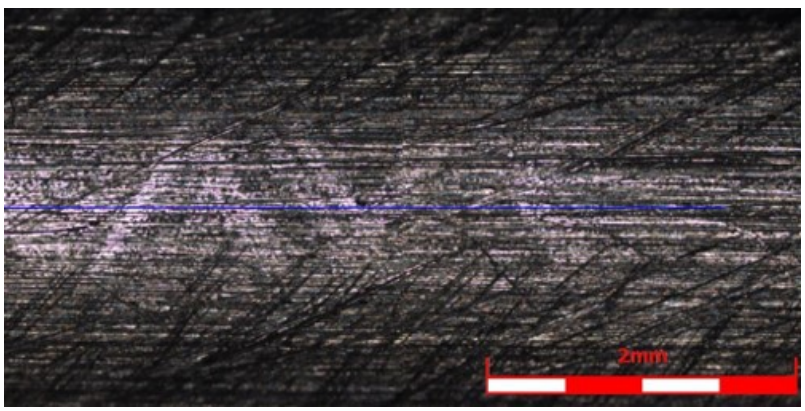

Figure 3. Surface of the tube
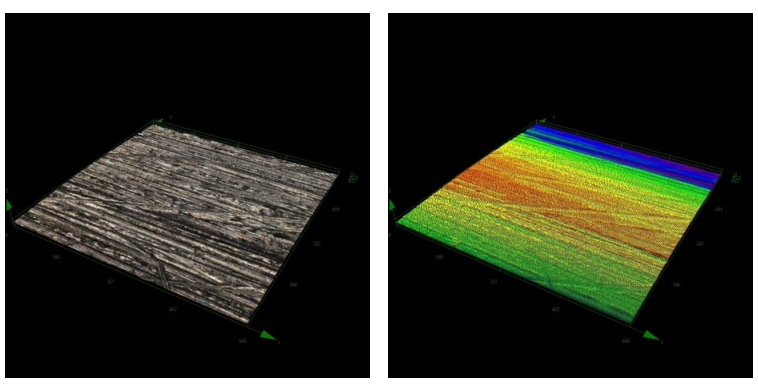

FiguRE 4. Microscopic image of abraded Inconel 625 tube

Another important finding was that the degassing procedure had to be done each time the loop was shut off. This was most likely caused by the dissolving of nitrogen into water, which was used to pressurize the loop.

The parameters of experiments with deviations from target values are shown in Tab. 3

\begin{tabular}{lrrr}
\hline Parameter & $\begin{array}{r}\text { Target } \\
\text { value }\end{array}$ & $\begin{array}{r}\text { Avg. } \\
\text { value }\end{array}$ & $\begin{array}{r}\text { Std. } \\
\text { dev. }\end{array}$ \\
\hline Mass flux & 400 & 399.2 & 5.1 \\
$G\left[\mathrm{~kg} /\left(\mathrm{m}^{2} . \mathrm{s}\right)\right]$ & 500 & 499.2 & 1.5 \\
& 600 & 597.7 & 3.1 \\
Inlet temperature & 64 & 64.07 & 0.43 \\
$T_{\text {in }}\left[{ }^{\circ} \mathrm{C}\right]$ & 78 & 78.30 & 1.43 \\
& 91 & 90.93 & 1.76 \\
Outlet pressure & 120 & 122.2 & 4.3 \\
$p_{\text {out }}[\mathrm{kPa}]$ & 200 & 199.2 & 12.5 \\
& 300 & 299.1 & 13.1 \\
\hline
\end{tabular}

TABLE 3. Experimental parameters with deviations
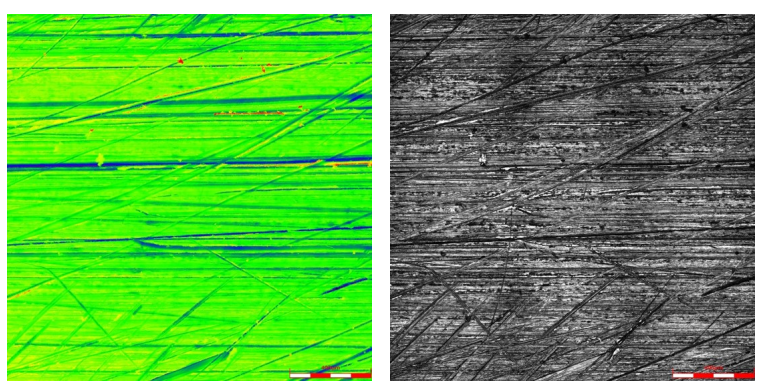

Figure 5. Detail of the tube surface
The measured quantities and their values are given in Tab. 4. The power is calculated by the multiplication of electric current and voltage. The heat flux is then estimated by dividing the power by the heated surface which is equal to $\pi \cdot d_{i n} \cdot L$, where $d_{i n}$ is the inner diameter of the annulus and $L$ is the heated length.

The relative deviation of the critical heat flux is calculated as:

$$
\frac{\Delta q}{q}=\frac{\Delta Q}{Q}+\frac{\Delta d_{i n}}{d_{i n}}+\frac{\Delta L}{L} .
$$

The mass flux is calculated by dividing the measured mass flow rate $F$ by the flow area of the annulus and the relative deviation can be therefore determined as:

$$
\frac{\Delta G}{G}=\frac{\Delta F}{F}+\frac{2 \cdot d_{\text {out }} \Delta d_{\text {out }}}{d_{\text {out }}^{2}-d_{\text {in }}^{2}}+\frac{2 \cdot d_{\text {in }} \Delta d_{\text {in }}}{d_{\text {out }}^{2}-d_{\text {in }}^{2}}
$$

\begin{tabular}{lll}
\hline Measured quantity & Range & Accuracy \\
\hline Pressure $[\mathrm{kPa}]$ & $100-300$ & $2.78 \mathrm{kPa}$ \\
Temp. inlet $\left[{ }^{\circ} \mathrm{C}\right]$ & $64-91$ & $0.3{ }^{\circ} \mathrm{C}$ \\
Mass flow $[\mathrm{kg} / \mathrm{hod}]$ & $152-229$ & $0.45 \%$ \\
Mass flux $\left[\mathrm{kg} /\left(\mathrm{m}^{2} / \mathrm{hod}\right)\right]$ & $400-600$ & $3.7 \%$ \\
Power $[\mathrm{kW}]$ & 30 & $0.6 \%$ \\
Heat flux $\left[\mathrm{kW} / \mathrm{m}^{2}\right]$ & $1050-2650$ & $1.7 \%$ \\
\hline
\end{tabular}

TABle 4. Accuracy of measurement devices

\subsection{Operational Experience}

Temperature of the surface rose above $500{ }^{\circ} \mathrm{C}$ several times during the boiling crisis and the dried-out spot started glowing. This happened due to a relatively long distance between thermocouples. That resulted in a delay between temperature excursion and its detection, whenever boiling crises happened in between TCs and at different sides of the test tube than the TCs were pressed to. Most of the time, glowing occurred at the top of the test section, but it could occur in the middle as well, see Fig. 6.

An example of observed glowing of the test section can be seen in the Figs. 7 and 8 , where the glowing spots are clearly visible.

As can be seen in the pictures, there is also a noticeable layer of oxides. This layer most likely consists of nickel oxides from the inconel and deposits from the loop, since the experimental loop components are mostly made of carbon steel. However, the effect of the oxide layer is not straightforward and will be the subject of further investigation.

Using a high speed camera, it was detected that prior to boiling crisis, dryout of the surface can occur without developing into CHF. Fig. 9 shows the evaporation of the liquid film and growth of the dry area. The dry area continues to grow, but Leidenfrost temperature was not exceeded and therefore the surface 

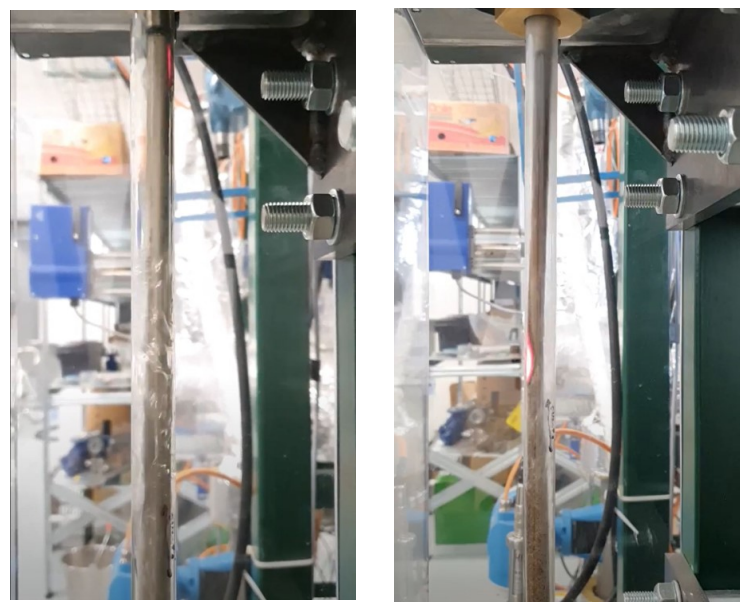

Figure 6. Glowing during $\mathrm{CHF}$

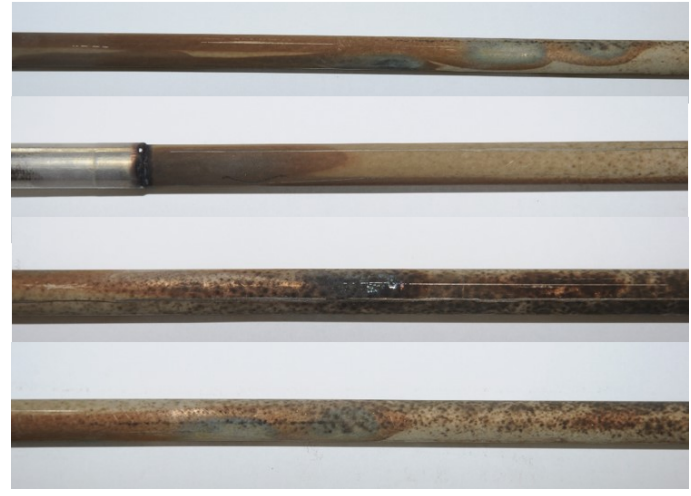

Figure 7 . Detail of the test section with post glowing spots

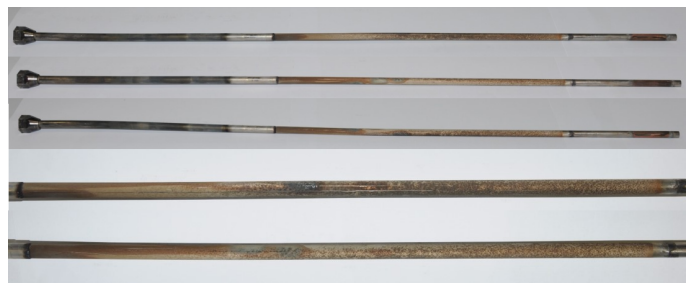

Figure 8. Test section after experiments

was rewetted as can be seen in the right picture in Fig. 10. This particular dryout incident happened between 7.3 and 7.2 seconds before $\mathrm{CHF}$ was reached 1

Figs. 11 and 12 show the developed boiling crisis during which glowing occurred. The picture on the left in Fig. 11 shows already developed boiling crisis. The darker shade of grey at the bottom of the highlighted area indicates the onset of glowing. Despite the high temperature, TCs did not detect CHF yet and the surface continued to heat un ${ }^{2}$. The picture on the right shows that the water came into contact with the surface, however the temperature was higher than the rewetting temperature and the water evaporated immediately after it interacted with the surface. The

\footnotetext{
${ }^{1}$ Each picture shows the same frame with and without highlighted parts.

${ }^{2}$ This happened $0.3 \mathrm{~s}$ before the detection.
}
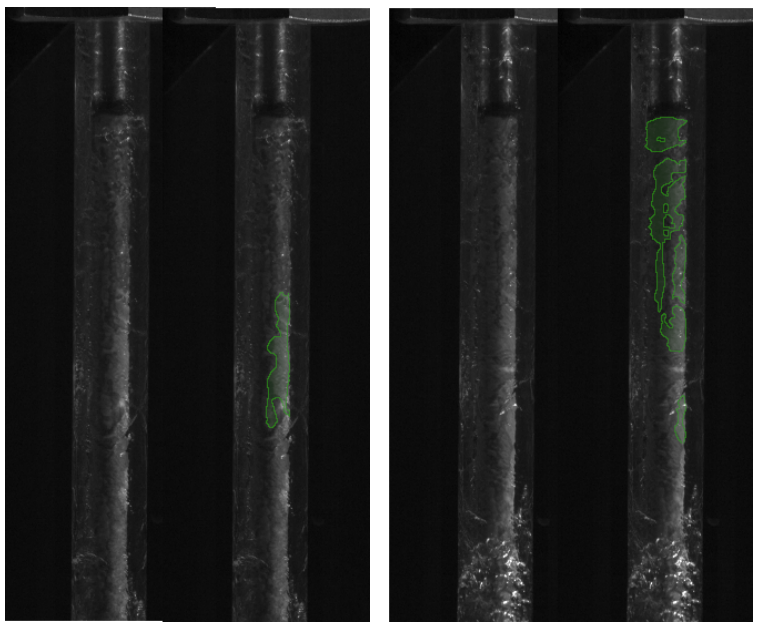

Figure 9. Dryout of tube surface
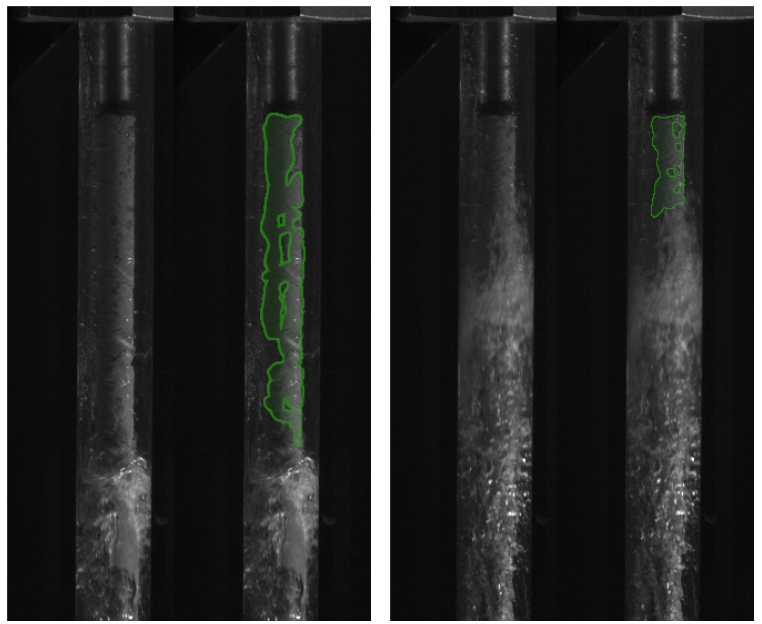

Figure 10. Rewetting of tube surface

moment when TCs detected temperature excursion is depicted in Fig. 12. On the right picture the power source is already turned off, nevertheless water does not rewet the surface right after the shut-down and water flows around the spot, this is visible at the bottom of the highlighted area.

\section{Results AND Discussion}

The critical heat flux values for different mass fluxes are shown in Fig. 13. Most of the experiments were conducted at mass fluxes of 400 and $600 \mathrm{~kg} /\left(\mathrm{m}^{2} . \mathrm{s}\right)$, but a few were done at $500 \mathrm{~kg} /\left(\mathrm{m}^{2} . \mathrm{s}\right)$.

The values differ substantially, as was mentioned above, some of the lowest values are unreliable due to the occurrence of oscillations. One of those instances was the experimental run at $400 \mathrm{~kg} /\left(\mathrm{m}^{2} . \mathrm{s}\right)$ and $120 \mathrm{kPa}$ with $\mathrm{CHF}$ value of $1090 \mathrm{~kW} / \mathrm{m}^{2}$, captured on the camera (Fig. 11). The experiment was rushed and it led to instabilities, there was a pause between runs and the condenser cooled down, it would be desirable to keep heating up the loop longer than was the case with other experiments.

The same is the case for the lowest CHF value, 

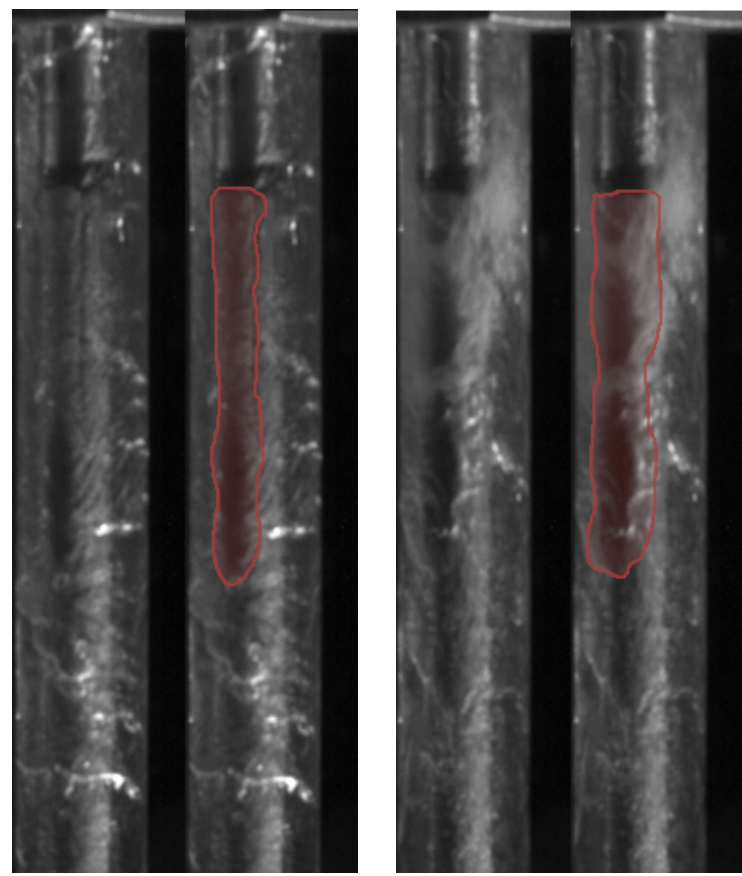

Figure 11. Glowing during CHF

while more than half of the results at $120 \mathrm{kPa}$ and 400 $\mathrm{kW} / \mathrm{m}^{2}$ varied between $1350-1450 \mathrm{~kW} / \mathrm{m}^{2}$, the lowest recorded CHF value was $825 \mathrm{~kW} / \mathrm{m}^{2}$. Thus it can be assumed that values lower than $1200 \mathrm{~kW} / \mathrm{m}^{2}$ are not reliable. This was the first experiment of the day, the degassing procedure was done the day before, and the heating period was too short. Similarly, the lowest value for $300 \mathrm{kPa}$ and $400 \mathrm{~kg} /\left(\mathrm{m}^{2} . \mathrm{s}\right)$ is inaccurate because it was the first experiment of the day and the loop was not properly heated up. In general, the first experiments on any given day did not yield trustworthy results.

The trend of ramping up power is depicted in Figs. 15 17 and 19 which show TCs temperatures during runs. Each experimental run started with a $15 \mathrm{~min}$ heating period, followed by a slow continuous increase in supplied power. The power increase was usually between 15 and $20 \mathrm{~kW}$ over $30 \mathrm{~min}$ depending on the mass flow and pressure, as can be seen from the linear growth of temperature. CHF was reached during this period, the sudden increase of temperature is also visible in the graphs. Preceding the temperature excursion and $\mathrm{CHF}$, there seems to be a higher variation of temperature in the test section.

This might indicate surface dryout and re-wetting without reaching boiling crisis, this could be one of the reasons of the relatively high discrepancy between results. Nevertheless, flow boiling is a highly dynamic process and most of the results for the same parameters are within $100 \mathrm{~kW} / \mathrm{m}^{2}$ range from each other.

Pressure graphs in Figs. 14,16 and 18 show oscillations of inlet pressure, this does not affect the outlet pressure too much, however it still has a negative effect on the experiments. This is most likely caused by the hoses that connect the test section with the
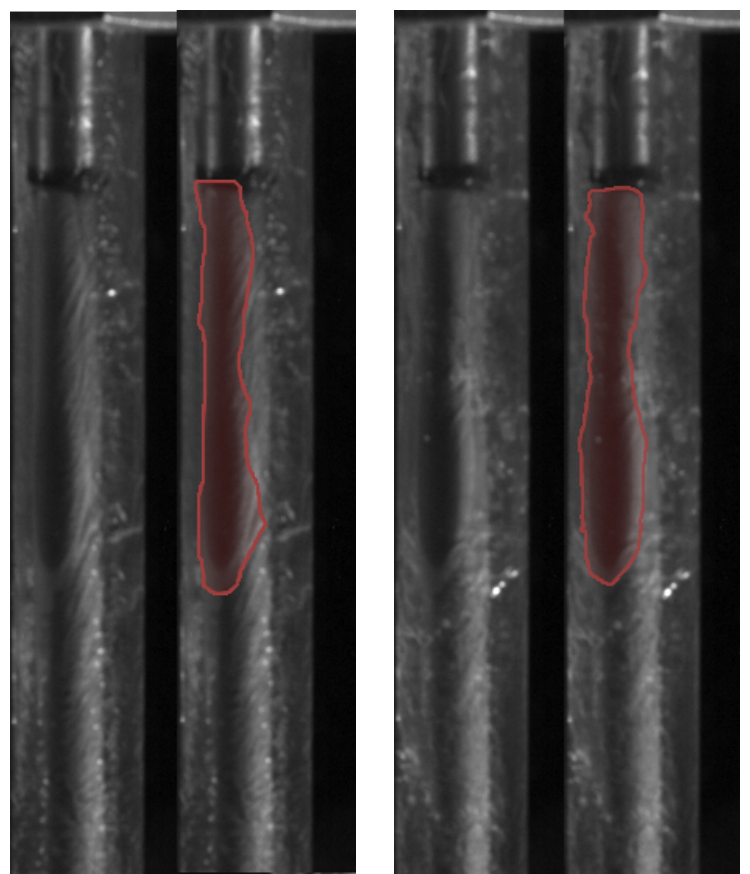

Figure 12. Post CHF overheated surface

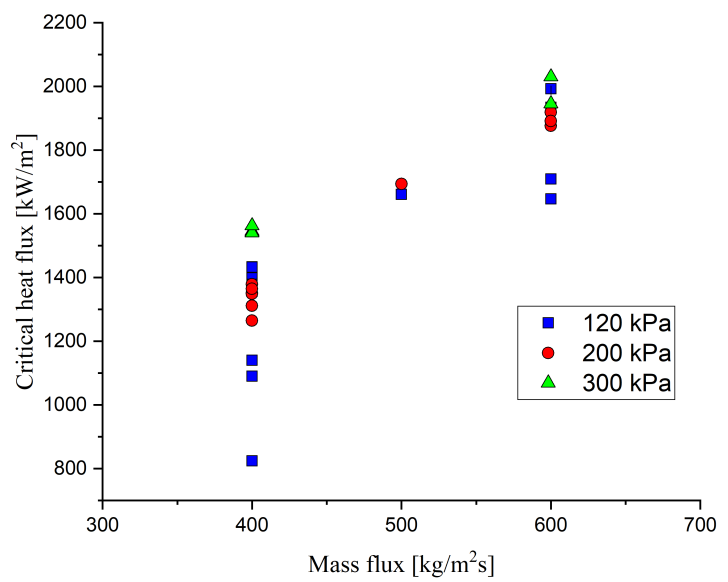

FiguRE 13. Results of the experiments

preheater, a throttling valve is placed directly behind the preheater, thus allowing the inlet pressure to be affected by dynamic changes of the flow within the test section.

It is assumed that the situation would be improved by moving the throttling valve directly in front of the test section to minimize the volume of water between the valve and the inlet of the section. Another issue is the rigidness of the hoses, which is much lower than steel tubes and allows for a higher level of vibration.

\section{Conclusion}

The flow boiling CHF experiments were done using the annular geometry of the test section, heated by DC power source. The experiments were performed on Inconel 625 tube abraded with 150 grit sandpaper at low pressure and low flow. 


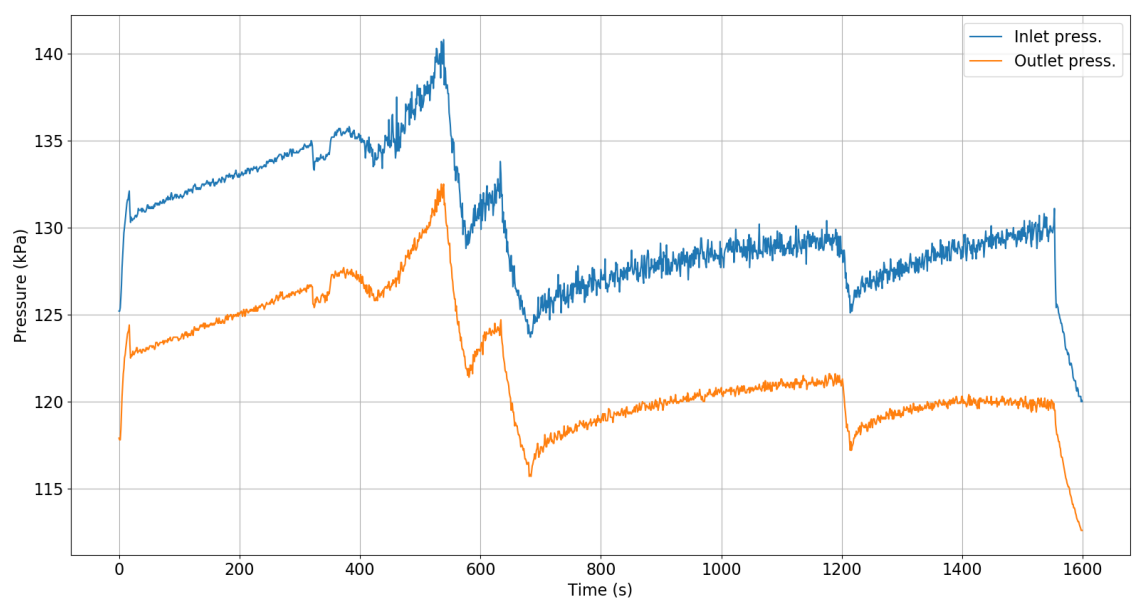

Figure 14. Pressures during $120 \mathrm{kPa}$ and $400 \mathrm{~kg} /\left(\mathrm{m}^{2} . \mathrm{s}\right)$

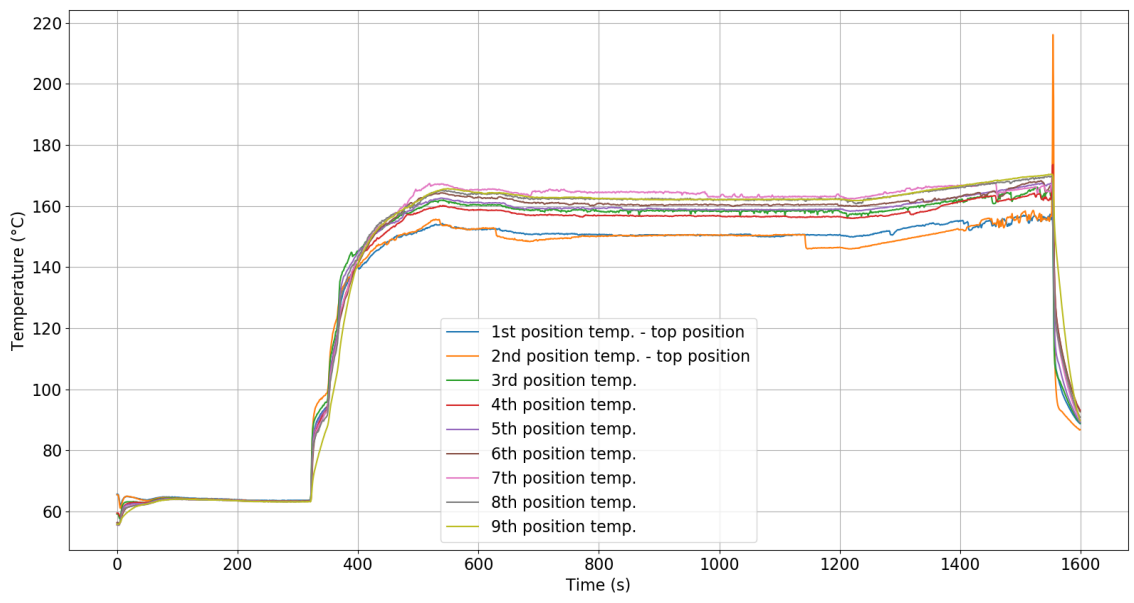

Figure 15. Temperatures during $120 \mathrm{kPa}$ and $400 \mathrm{~kg} /\left(\mathrm{m}^{2} . \mathrm{s}\right)$

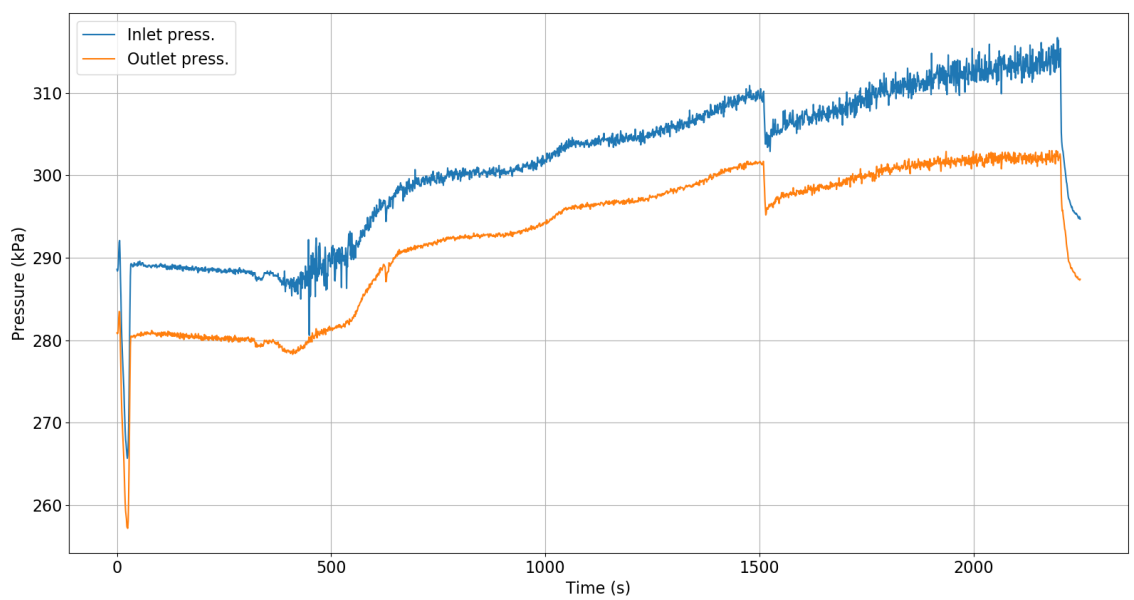

Figure 16. Pressures during $300 \mathrm{kPa}$ and $400 \mathrm{~kg} /\left(\mathrm{m}^{2} . \mathrm{s}\right)$ 


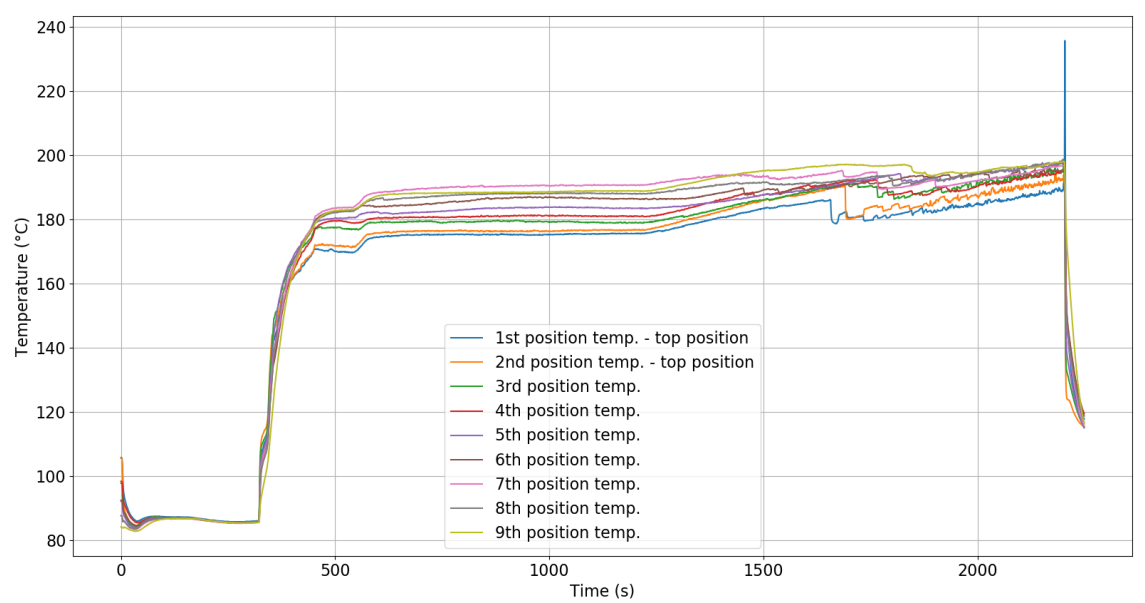

Figure 17. Temperatures during $300 \mathrm{kPa}$ and $400 \mathrm{~kg} /\left(\mathrm{m}^{2} . \mathrm{s}\right)$

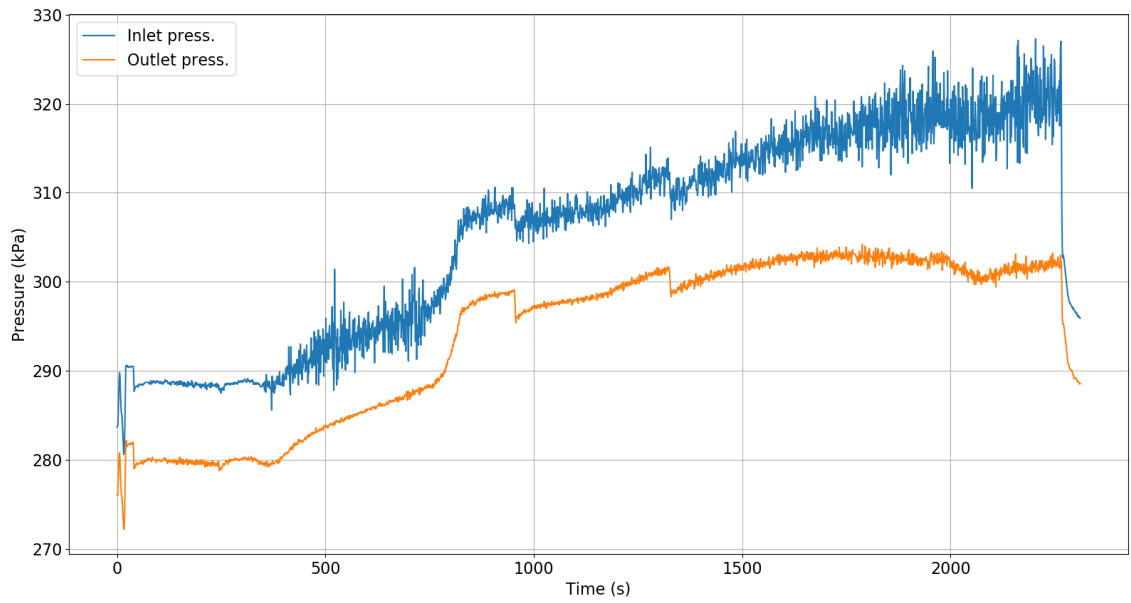

Figure 18. Pressures during $300 \mathrm{kPa}$ and $600 \mathrm{~kg} /\left(\mathrm{m}^{2} . \mathrm{s}\right)$

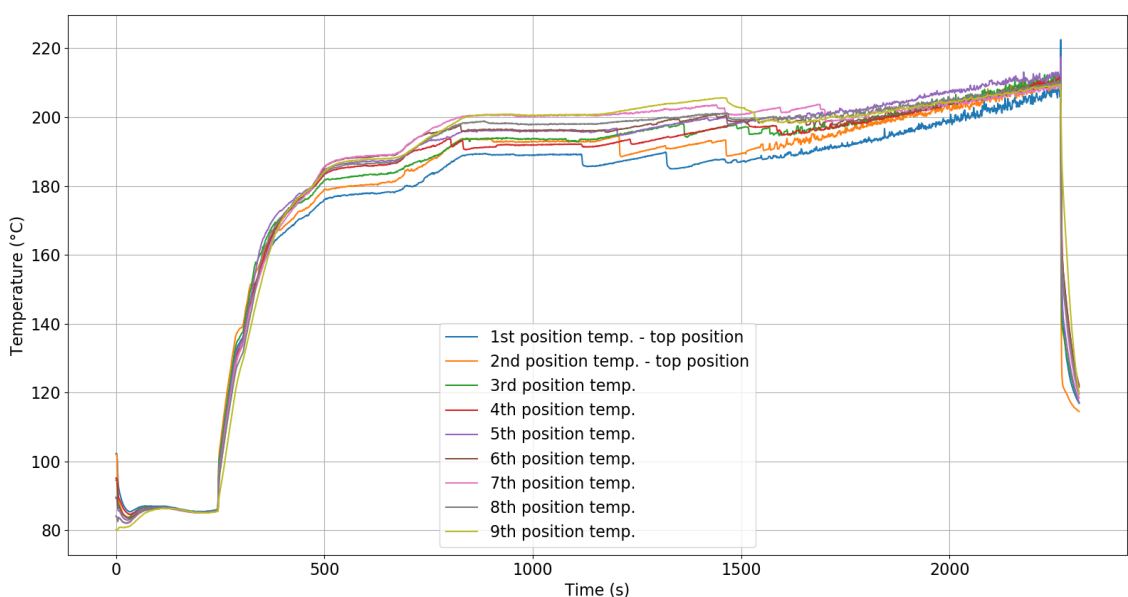

Figure 19. Temperatures during $300 \mathrm{kPa}$ and $600 \mathrm{~kg} /\left(\mathrm{m}^{2} . \mathrm{s}\right)$ 
The CHF was substantially affected by the startup sequence as it was important to properly heat up the loop to prevent excessive oscillations. After studying high-speed camera recordings, it was found out that the surface may dry out without overstepping Leidenfrost temperature and initiating a boiling crisis. This could be one of the reasons of the relatively high variations between results. Oxide layer formed on the tube surface during the investigation, however the exact nature of the layer and its effect on the $\mathrm{CHF}$ could not be discerned during this work and will be studied further.

These experiments will be followed by experiments on smooth and bead blasted surface and on smooth Zirlo tube. After these experiments the loop will be upgraded based on the knowledge and experience gained during the operation and it will be used to further study $\mathrm{CHF}$ at low pressure and flow, the effect of oxide layer on $\mathrm{CHF}$ and boiling crisis on ATF fuels.

\section{LIST OF SYMBOLS}

$d_{i}$ Inner diameter [mm]

$d_{o}$ Outer diameter $[\mathrm{mm}]$

$d_{h e}$ Heated equivalent diameter [mm]

$\delta$ Gap width [mm]

$F \quad$ Flow rate $\left[\mathrm{kg} \mathrm{s}^{-1}\right]$

$G$ Mass flux $\left[\mathrm{kg} \mathrm{m}^{-2} \mathrm{~s}^{-1}\right]$

$\Delta h_{\text {in }}$ Inlet subcooling [ $\left[\mathrm{kJ} \mathrm{kg}^{-1}\right.$ ]

$L$ Length [mm]

$p_{\text {in }}$ Inlet pressure $[\mathrm{kPa}]$

$q$ Heat flux $\left[\mathrm{kW} \mathrm{m}^{-2}\right]$

$T_{\text {in }}$ Inlet temperature $\left[{ }^{\circ} \mathrm{C}\right]$

$R_{s m}$ Mean width of the profile $[\mu \mathrm{m}]$

$R_{a}$ Roughness average $[\mu \mathrm{m}]$

$R_{t} \quad$ Max. height of the profile $[\mu \mathrm{m}]$

$R_{z} \quad$ Average max. height of the profile $[\mu \mathrm{m}]$

ATF Accident Tolerant Fuel

CHF Critical Heat Flux

BUT Brno University of Technology

\section{ACKNOWLEDGEMEnTS}

The research was supported by the project LTAUSA18198 and is part of a cooperation between BUT and Texas A\&M University. Another support was also possible via Czech Technical University in Prague with its Student grant contest project with the code SGS20/187/OHK4/3T/14. Authors are thankful to their supervisor and PI of the project, Karel Katovsky, Ph.D., for his support and advice during the project.

\section{REFERENCES}

[1] H. O'Hanley, C. Coyle, J. Buongiorno, et al. Separate effects of surface roughness, wettability, and porosity on the boiling critical heat flux. Applied Physics Letters 103 (2)(2):1-5, 2013-07-08. DOI:10.1063/1.4813450

[2] D. H. Kam, J. H. Lee, T. Lee, Y. H. Jeong. Critical heat flux for sic- and cr-coated plates under atmospheric condition. Annals of Nuclear Energy 76:335-342, 2015. DOI:10.1016/j.anucene.2014.09.046
[3] A. F. Ali, J. P. Gorton, N. R. Brown, et al. Surface wettability and pool boiling critical heat flux of accident tolerant fuel cladding-fecral alloys. Nuclear Engineering and Design 338:218-231, 2018. DOI:10.1016/j.nucengdes.2018.08.024

[4] G. Liang, Y. Chen, H. Yang, et al. Nucleate boiling heat transfer and critical heat flux (chf) from micro-pit surfaces. International Journal of Heat and Mass Transfer 152:119970, 2020. DOI:10.1016/j.ijheatmasstransfer.2020.119510

[5] Thermohydraulic Relationships for Advanced Water Cooled Reactors. IAEA, Vienna, 1st edn., 2001.

[6] C. Haas, L. Meyer, T. Schulenberg. Flow instability and critical heat flux for flow boiling of water in a vertical annulus at low pressure. ASME/JSME 2011 8th Thermal Engineering Joint Conference 2011:11, 2011-03-13. DOI:10.1115/AJTEC2011-44292.

[7] C. Haas, T. Schulenberg, T. Wetzel. Critical heat flux for flow boiling of water at low pressure in vertical internally heated annuli. International Journal of Heat and Mass Transfer 60:380-391, 2013.

DOI:10.1016/j.ijheatmasstransfer.2012.12.038

[8] S.-Y. Chun, H.-J. Chung, S.-K. Moon, et al. Effect of pressure on critical heat flux in uniformly heated vertical annulus under low flow conditions. Nuclear Engineering and Design 203(2-3):159-174, 2001. DOI:10.1016/S0029-5493(00)00307-1.

[9] M. P. Fiori, A. E. Bergles. Model of critical heat flux in subcooled flow boiling. Cambridge, Mass. : M.I.T. Dept. of Mechanical Engineering, 1968.

[10] M. S. El-Genk, S. J. Haynes, K. Sung-Ho. Experimental studies of critical heat flux for low flow of water in vertical annuli at near atmospheric pressure. International Journal of Heat and Mass Transfer $\mathbf{3 1}$ (11)(11):2291-2304, 1988. DOI:10.1016/0017-9310(88)90161-5.

[11] T. Schoesse, M. Aritomi, Y. Kataoka, et al. Critical heat flux in a vertical annulus under low upward flow and near atmospheric pressure. Journal of Nuclear Science and Technology 34 (6)(6):559-570, 1997. DOI:10.1080/18811248.1997.9733709.

[12] J. T. Rogers, M. E. Salcudean, A. E. E. Tahir. Flow boiling critical heat fluxes for water in a vertical annulus at low pressure and velocities. Proceeding of International Heat Transfer Conference 7 pp. 339-344, 1982. DOI:10.1615/IHTC7.1180.

[13] K. Mishima, H. Nishihara. Effect of channel geometry on critical heat flux for low pressure water. International Journal of Heat and Mass Transfer 30 (6):1169-1182, 1987. DOI:10.1016/0017-9310(87)90046-9.

[14] G. Mayer, R. Nagy, I. Nagy. An experimental study on critical heat flux in vertical annulus under low flow and low pressure conditions. Nuclear Engineering and Design 310:461-469, 2016.

DOI:10.1016/j.nucengdes.2016.10.026

[15] D. Vlcek, L. Suk, K. Stevanka, T. Petrosyan. EXPERIMENTAL INVESTIGATION OF CRITICAL HEAT FLUX IN ANNULUS AT LOW PRESSURE AND LOW FLOW PARAMETERS [preprint]. Acta Polytechnica CTU Proceedings 2020.

[16] ČSN EN ISO 4288. Czech Office for Standards, Metrology and Testing, 1999. 